\title{
Silver nanoparticle release from commercially available plastic food containers into
} food simulants

\author{
Mackevica, Aiga; Olsson, Mikael Emil; Hansen, Steffen Foss
}

Published in:

Journal of Nanoparticle Research

Link to article, DOI:

$10.1007 / \mathrm{s} 11051-015-3313-x$

Publication date:

2016

Document Version

Peer reviewed version

Link back to DTU Orbit

Citation (APA):

Mackevica, A., Olsson, M. E., \& Hansen, S. F. (2016). Silver nanoparticle release from commercially available plastic food containers into food simulants. Journal of Nanoparticle Research, 18(1), [5]. https://doi.org/10.1007/s11051-015-3313-x

\section{General rights}

Copyright and moral rights for the publications made accessible in the public portal are retained by the authors and/or other copyright owners and it is a condition of accessing publications that users recognise and abide by the legal requirements associated with these rights.

- Users may download and print one copy of any publication from the public portal for the purpose of private study or research.

- You may not further distribute the material or use it for any profit-making activity or commercial gain

- You may freely distribute the URL identifying the publication in the public portal 


\title{
Silver nanoparticle release from commercially available plastic food containers into food simulants
}

Aiga Mackevica*, Mikael Emil Olsson, Steffen Foss Hansen

Department of Environmental Engineering, Technical University of Denmark, Miljoevej Building 113, 2800

Kgs. Lyngby, Denmark.

*Corresponding author. E-mail: aima@env.dtu.dk, phone: +45 4525 1477, fax: +45 45932850

\begin{abstract}
Silver nanoparticles (AgNPs) are currently being used in many different kinds of consumer products in order to take advantage of their antimicrobial properties. However, the potential migration of silver nanoparticles into food and subsequent consumer exposure has hardly been addressed. In the current study, we investigated for four brands of commercially available plastic food storage containers and measured the total amount of silver, particle size and number concentration, and the migration rates into three different food simulants (MilliQ grade water, $10 \%$ ethanol, and $3 \%$ acetic acid) for 10 days at $40^{\circ} \mathrm{C}$. The experimental setup was according to the European Commission Directive (EU 10/2011) for articles intended to be in contact with food. The total amount of silver in plastic containers and migration solutions was quantified by ICP-MS analysis, and the size of the migrated particles was investigated by single particle ICP-MS and TEMEDS. The total mass and median size of released particulate Ag was generally highest in $3 \%$ acetic acid for three out of four food container brands. The total content of silver in the containers varied from 13 to 42 $\mu \mathrm{g} / \mathrm{g}$. The highest migration was observed in the $3 \%$ acetic acid food simulant for all four brands of containers, with total silver release up to $3.1 \mathrm{ng} / \mathrm{cm}^{2}$ after 10 days. In conclusion, the experimental results show that silver has the potential of migrating into food, especially when in contact with more acidic substances.
\end{abstract}


Keywords: Silver nanoparticles, Consumer products, Nanoparticle release, Consumer exposure

\section{Acknowledgements}

This project has received funding from the European Union's Seventh Framework Programme [FP7/20072013] under EC-GA No. 604305 'SUN'. We sincerely thank our lab technicians Susanne Kruse and Sinh Hy Nguyen for their contribution to this work. 


\section{Introduction}

Silver nanoparticles (AgNPs) are used for wide range of applications, mostly due to their ability to release silver ions that are proven to be an effective biocide. Because of their antimicrobial properties AgNPs are applied as inner coatings for various food storage containers, such as plastic bags or boxes, in order to keep the food fresh longer (The Nanodatabase 2015; The Project on Emerging Nanotechnologies (PEN) 2013). From a consumer point of view, it is beneficial to have an antimicrobial agent in the food contact materials, to increase the shelf-life of food and to store it for a longer time. However, the health risks associated with the use of such products is a major knowledge gap, which needs to be addressed.

Quite recently AgNP-enabled consumer products, food containers among them, have gained a lot of attention. The production and use of AgNPs in food contact materials has not been prohibited in most countries and AgNP-enabled food packaging materials are freely available to consumers. However, as of March 2014 United States Environmental Protection Agency (US EPA) has banned the production and sales of several brands of plastic food containers that contain silver nanoparticles, due to the lack of proper testing, to ensure consumer safety (US EPA 2014). Later in 2014, the Center for Food Safety (CFS), a nongovernmental organization, filed a petition against the U.S. EPA over their inability to regulate nano-scale pesticides, as a large number of them are still commercially available (CFS 2014). CFS and PEN database had identified over 400 products containing nanosilver on the market as of December 2014 (CFS 2014), whereas on The Nanodatabase there are around 300 nanosilver-containing consumer products identified (The Nanodatabase 2015).

There have been attempts to quantify the total Ag release rates from various consumer products, including food contact materials (von Goetz et al. 2013; Huang et al. 2011; Hauri and Niece 2011; Song et al. 2011; Bott et al. 2011; Smirnova et al. 2012; Echegoyen and Nerín 2013; Cushen et al. 2014; Artiaga et al. 2014). One of the first publications addressing Ag release from food storage containers was by Huang et al. (2011), 
who assessed the release from polyethylene bags incubating them with different food simulants, such as deionized water, $4 \%$ acetic acid, $95 \%$ ethanol and hexane for 15 days and found indications of the presence of $\mathrm{Ag}$ in the plastic bags and analysis by Scanning Electron Microscopy (SEM) coupled with Energy Dispersive X-ray Spectroscopy (EDS) confirmed AgNPs release. Another study by Hauri and Niece (2011) used a similar release setup and tested commercially available plastic food storage containers advertised as containing AgNPs and found that acetic acid resulted in higher Ag release rates compared to ethanol and distilled water. However, Hauri and Niece (2011) did not quantify the initial Ag content of the food containers or the Ag release in the nanoparticulate form. Again, using a similar setup, experimental studies by von Goetz et al. (2013) and Artiaga et al. (2014) also chose to test the migration of AgNPs from commercially available food storage materials. Instead of using intact food containers, von Goetz et al. (2013) cut the food containers into pieces and exposed them to food simulants. Von Goetz et al. (2013) showed that the release rates per available surface area were considerably increased if the food containers from the same brand were kept intact, but they also noted that containers had an inhomogeneous distribution of $\mathrm{Ag}$ in different parts, as well as different total Ag concentrations. Furthermore, von Goetz et al. (2013) found that Ag migration dropped by a factor up to 10 between the first and subsequent use of food containers in a multiple use scenario. This is important as food containers are very often used more than once. A similar trend was observed in similar study by Echegoyen and Nerín (2013) with multiple uses of containers.

The overall conclusion from the experiments performed so far is that consumer exposure is negligible, as the amounts leached from the food containers are found to be very low and in the magnitudes of $\mathrm{ng} / \mathrm{cm}^{2}$. All the studies have so far reported Ag migration in the form of total ionic silver, not going much into size distributions of the particulate fraction (if any). Therefore the question remains whether or not there is a release of silver in the nano-form, and how the available analytical methods can be applied to characterize the particle release. It is well known that AgNPs have different toxicological properties compared to ionic 
and bulk silver and the release of AgNPs could have implications for human health risks exposure and risk assessment. There is a great need for quantification and characterization of consumer exposure to Ag nanoparticles, as the information of the total $\mathrm{Ag}$ exposure is not sufficient to assess the actual risks.

In this study, we aimed at quantifying the Ag migration from four different commercially available food container brands that advertise AgNP as an ingredient in their product. Apart from assessing the total $\mathrm{Ag}$ release, we also investigated the release of $\mathrm{Ag}$ in the nano-particulate form by transmission electron microscopy (TEM) and single particle inductively coupled plasma mass spectrometry (spICP-MS). This study attempts to go further than just quantifying total $\mathrm{Ag}$ release from food containers, utilizing state of the art nanoparticle characterization techniques to provide information on nanoparticulate and dissolved $\mathrm{Ag}$ release. To the best of our knowledge, this is the first study to present the AgNP release from food containers in a quantitative manner, including size distributions of the released particles.

\section{Materials and methods}

\section{Food container samples}

Four different commercially available plastic food containers were purchased through Amazon.com, where two of them were polyethylene (PE) food storage boxes (Kinetic Go Green ${ }^{\mathrm{TM}}$ Premium Food Storage Containers (Kinetic, USA), and The Original Always Fresh Containers ${ }^{\mathrm{TM}}$ (Gourmet Trends, USA)), one was PE zipper storage bag (Fresher Longer ${ }^{\mathrm{TM}}$ Miracle Food Storage ${ }^{\mathrm{TM}}$ bags (Sharper Image, USA)), and one was high density polyethylene (HDPE) bag for breast milk storage (Special Nanosilver Mother's milk pack (Jaco, Korea)). All of these products are listed in The Nanodatabase (The Nanodatabase 2015) and the product information for all four products indicated that they contain silver nanoparticles for antimicrobial and antifungal purposes. The appearance of those products is shown in Figure 1, and manufacturer product information can be found in The Nanodatabase (2015). Kinetic Go Green ${ }^{\mathrm{TM}}$ Premium has been banned by 
the US EPA, but it is still available for purchase in various online shops, such as amazon.co.uk, as indicated in The Nanodatabase (2015).

Pure polyethylene spherical granulates were obtained from BASF (Germany), and were used as a control (no Ag added from the manufacturer).

\section{Release testing}

The release tests were set up and performed following the EU regulation 10/2011 for plastic materials and articles intended to be in contact with food (European Commission 2011). Three food simulants were selected for migration testing: Milli-Q water, $3 \%$ acetic acid, and $10 \%$ ethanol. Food containers with food simulants were sealed and incubated at $40^{\circ} \mathrm{C}$ for 10 days. The volume of added food simulant was dependent on the size of the container. The main criterion for the added volume of food simulant was that it had to completely cover the bottom part for the food storage boxes, or cover a sufficient surface area for plastic bags (i.e. around half of total available volume). For zipper storage bags and milk storage bags the added volume was $75 \mathrm{~mL}$, and for Kinetic Go Green ${ }^{\mathrm{TM}}$ containers $100 \mathrm{~mL}$, whereas for The Original Always Fresh Containers ${ }^{\mathrm{TM}}$, where the containers were with different sizes, the added volumes were $100 \mathrm{~mL}$ (MilliQ), $50 \mathrm{~mL}$ (10\% ethanol) and $45 \mathrm{~mL}$ (3\% acetic acid).

As a silver-free control, two grams of polyethylene granulates were immersed into $5 \mathrm{~mL}$ of the same food simulants for 10 days at $40^{\circ} \mathrm{C}$ in plastic tubes with stoppers. The tubes were prepared in triplicates for each food simulant.

\section{Chemical analysis of food containers}

The total content of $\mathrm{Ag}$ in food containers was analyzed by using inductively coupled plasma mass spectrometer (ICP-MS) (7700x, Agilent Technologies). For sample preparation, the plastic food containers were frozen with liquid nitrogen and crushed into small $(<2 \mathrm{~mm})$ pieces using cutting mill (Retsch) to obtain a representative sample. Then, $0.25 \mathrm{~g}$ of digested following a method that has been proven being effective 
for plastic food packaging containing silver (Lin et al. 2011) using $6 \mathrm{~mL}$ concentrated $\mathrm{HNO}_{3}$ and $2 \mathrm{~mL}$ concentrated $\mathrm{H}_{2} \mathrm{SO}_{4}$. Samples were digested by microwave-assisted digestion (Multiwave 3000, Anton-Paar) at $210^{\circ} \mathrm{C}$ for $20 \mathrm{~min}$. Digested samples were further diluted with Milli-Q water and analyzed using ICP-MS. As there is no certified standard reference material available for AgNPs in a plastic matrix, the validity of the method was tested by spiking some of the samples with known amounts of $30 \mathrm{~nm}$ silver nanoparticles (Cline Scientific, Sweden). All analyses were performed as triplicates.

\section{Chemical analysis of migration solutions}

The total amount of Ag migrated into food simulants was tested by digesting $3.0 \mathrm{~mL}$ of migration solutions with $1.5 \mathrm{~mL}$ of concentrated $\mathrm{HNO}_{3}$ for 24 hours at room temperature. Subsequently, the digested samples were diluted and total $\mathrm{Ag}$ content was measured by ICP-MS. As above, $30 \mathrm{~nm} \mathrm{Ag} \mathrm{particles} \mathrm{was} \mathrm{used} \mathrm{as}$ digestion control.

To obtain information about particles that may have migrated into solutions, samples were analyzed by single particle ICP-MS (spICP-MS), applying $3 \mathrm{~ms}$ dwell time, $7 \mathrm{~mm}$ sample cone depth and having a sampling time of $60 \mathrm{~s}$. The calculations of particle size and number distribution were performed according to a previously published method (Pace et al. 2011), assuming that released particles have spherical shape.

\section{Microscopy}

To confirm the presence of particles in the migration solutions and obtain information on their size and shape, transmission electron microscopy (TEM) analysis was performed. After release experiments, food simulant samples were prepared for TEM analysis by transferring $1 \mathrm{~mL}$ of sample into Eppendorf tubes, centrifuging them for $30 \mathrm{~min}$ at $10000 \mathrm{rpm}$, and then evaporating them in the fume hood for two days in order to obtain a more concentrated sample. Afterwards $4 \mu \mathrm{L}$ of the remaining sample was deposited on a copper grid covered with carbon film (Agar Scientific) and dried for approximately 4 hours under a petri dish in a fume hood. The TEM (Tecnai G2, FEI) was operated at $200 \mathrm{keV}$ accelerating voltage, and the 
composition of the particles found on the grid were investigated using energy dispersive X-ray spectroscopy (EDS) detector (Oxford Instruments).

\section{Results and discussion}

\section{Determination of total silver content in food containers}

After the microwave-assisted acid digestion the ICP-MS analysis of the total Ag content of unused containers showed that Special Nanosilver Mother's milk pack had the highest weight/weight content of Ag $(31.2 \pm 4.8 \mu \mathrm{g} / \mathrm{g})$, whereas The Original Always Fresh Containers ${ }^{\mathrm{TM}}$ had the highest Ag content per area (1.4 $\pm 0.4 \mu \mathrm{g} / \mathrm{cm}^{2}$ ). The measured Ag content in Kinetic Go Green ${ }^{\mathrm{TM}}$ samples was either very close to the detection limit ( 1 out of 3 replicates) or below detection limit of the method. As the containers were of different thickness, Kinetic Go Green ${ }^{\mathrm{TM}}$ containers being the thickest, total silver content is presented in both $\mu \mathrm{g} / \mathrm{g}$ and $\mu \mathrm{g} / \mathrm{cm}^{2}$ (Table 2). The detection limit was calculated from the average of blank samples $(\mathrm{n}=7)$ and adding 3 standard deviations, and the recovery for $30 \mathrm{~nm} \mathrm{Ag} \mathrm{NPs} \mathrm{that} \mathrm{were} \mathrm{used} \mathrm{to} \mathrm{check} \mathrm{the} \mathrm{validity}$ of digestion method was $110 \pm 1 \%$.

The total silver content in Fresher Longer ${ }^{\mathrm{TM}}$ Miracle Food Storage ${ }^{\mathrm{TM}}$ bags has been tested before in several studies. Echegoyen and Nerin (2013) found the Ag content to be $3.3 \mu \mathrm{g} / \mathrm{g}\left(0.02 \mathrm{mg} / \mathrm{cm}^{2}\right)$, whereas Artiaga et al. (2014) and von Goetz et al. (2013) found $28 \mu \mathrm{g} / \mathrm{g}$ and $37 \mu \mathrm{g} / \mathrm{g}$, respectively. The Ag content determined by our analysis resulted in about $22 \mu \mathrm{g} / \mathrm{g}$, which is in the same range with two of the three aforementioned studies (Artiaga et al, 2014, von Goetz et al, 2013). However, it is difficult to put these studies in parallel, as they have been using different analytical methods, e.g. Echegoyen and Nerin (2013) prepared plastic sample for ICP-MS analysis by weighing $1 \mathrm{~g}$ of sample and calcinating it at $600^{\circ} \mathrm{C}$ and digesting the ashes with $\mathrm{HNO}_{3}$. Artiaga et al. (2014) used only $0.1 \mathrm{~g}$ of sample for microwave digestion with $\mathrm{HNO}_{3}$ and $\mathrm{H}_{2} \mathrm{O}_{2}$. Another reason for different results is the lack of a reference sample to check for the full 
recovery of total Ag content in the sample matrix. Most likely all of these studies have used different batches of the product, which might be yet another reason for the lack of consensus in the measured values.

\section{Determination of silver release into food simulants}

Total silver and nano silver release was measured using two different techniques - acid digestion followed by ICP-MS analysis, and single particle ICP-MS analysis, respectively. When it comes to total Ag release, the highest migration from the food containers was observed in the $3 \%$ acetic acid food simulant for all four brands of containers. Total silver release was ranging from 2.0 to $3.1 \mathrm{ng} / \mathrm{cm}^{2}$ after 10 days (Table 2), the lowest release being for Fresher Longer ${ }^{\mathrm{TM}}$ bags and the highest for Special Nanosilver Mother's milk pack. The silver migration into MilliQ water and $10 \%$ ethanol was below detection limit for all samples (detection limit was calculated from the average of blank samples and adding 3 standard deviations). The Special Nanosilver Mother's milk pack showed the highest release per $\mathrm{cm}^{2}$, though the highest concentration in the solution was observed for The Original Always Fresh Containers ${ }^{\mathrm{TM}}$. The higher amounts of Ag released into acetic acid in comparison to $10 \%$ ethanol or MilliQ water was expected, knowing that $\mathrm{Ag}$ ion release rates tend to increase with decreasing $\mathrm{pH}$ values (Liu and Hurt 2010).

Comparing total $\mathrm{Ag}$ content and total $\mathrm{Ag}$ release both on weight/weight basis and weight/area basis (Table 1, Table 2), there is no apparent pattern regarding total Ag content and release depending on the food container brand. That could indicate that the production methods might be different, some brands resulting in more loosely bound particles, or different size and/or coatings of particles that could facilitate or hinder the silver ion or particle release. The atomic force microscopy (AFM) analysis reported by von Goetz et al. (2013) showed that the surface of food containers can be quite rough and have up to $10 \mu \mathrm{m}$ variations in height, which might have a large effect on the actual surface area in comparison to the measured surface area assuming a smooth surface. 
The microscopy results (TEM-EDS analysis) indicated AgNP release from all four commercial food container brands (Figure 2). The typical EDS spectrum of the particles is shown in Figure 3. As shown in the images, particles can be either freely dispersed in the suspension (Figure $2 \mathrm{C}$ and $\mathrm{E}$ ), or agglomerated (Figure $2 \mathrm{~A}$ and $\mathrm{D}$ ), or still embedded in or attached to the pieces of the polymer matrix (Figure $2 \mathrm{~B}$ and F). The primary particle sizes of $10-40 \mathrm{~nm}$ were found for Fresher Longer ${ }^{\mathrm{TM}}$ Miracle Food Storage ${ }^{\mathrm{TM}}$ bags, $10-100 \mathrm{~nm}$ for Special Nanosilver Mother's milk packs, around $100 \mathrm{~nm}$ for The Original Always Fresh Containers ${ }^{\mathrm{TM}}$, and 20 - $30 \mathrm{~nm}$ for Kinetic Go Green ${ }^{\mathrm{TM}}$ Premium Food Storage Containers. Unfortunately, due to the very low amounts of $\mathrm{Ag}$ released, a quantitative indication of AgNP sizes, shapes and agglomeration was not possible. The same goes for indication of whether the particles tend to occur freely in the food simulants or stay attached to the polymer matrix. Moreover, it must be noted that a major limitation of data interpretation from TEM imaging is the possible introduction of artifacts during sample preparation and drying (Tiede et al. 2008).

In two of the four brands of food storage containers (i.e. Fresher Longer ${ }^{\mathrm{TM}}$ and Kinetic Go Green ${ }^{\mathrm{TM}}$ ) apart from the AgNPs there were found also some particles containing titanium (Figure 4, Figure 5). It was both single particles (Figure 4 B, C, E, F) and agglomerates (Figure 4 A and D) observed in the primary particle sizes ranging between 50 and $200 \mathrm{~nm}$. It is not uncommon to have titanium dioxide added as a white pigment for plastics, or as an additive to absorb UV-light to prevent discoloration of the plastics and UVdamage (DuPont 2013). However, the addition of titanium dioxide $\left(\mathrm{TiO}_{2}\right)$ in the nanoscale is rarely advertised and reported in plastic products, and to the best of our knowledge, there is only one scientific study published addressing $\mathrm{TiO}_{2}$ release from food packaging (Li et al. 2014).

To obtain quantitative information regarding the amount of released Ag ions and particles, as well as the size distribution of Ag NPs, spICP-MS measurements were performed, analyzing the food simulants after 10 
days if incubation into food containers. The measurements were performed without any dilution or other kinds of sample preparation. The results from spICP-MS analysis showed a general trend that the amount of dissolved Ag was the highest for $3 \%$ acetic acid for all four brands of food containers. The total mass of particulate Ag was generally highest in $3 \%$ acetic acid, except for Fresher Longer ${ }^{\mathrm{TM}}$ bags (Table 3 ). This is also consistent with the data from total Ag release, which showed that acetic acid was facilitating the $\mathrm{Ag}$ release (Table 2). Echegoyen and Nerin (2013) also observed increased amounts of dissolved $\mathrm{Ag}$ in $3 \%$ acetic acid in comparison to $10 \%$ ethanol with spICP-MS analysis; however, they did not report the size of the particles.

The size distributions of released particles were quite similar for MilliQ and $10 \%$ ethanol, but the diameter of particles released into acetic acid were considerably higher for all container brands, except for Fresher Longer $^{\mathrm{TM}}$ bags, which only had dissolved Ag present in the sample (Figure 6). Evidently acetic acid facilitates both dissolution and aggregation/agglomeration of AgNPs, and also the possibility of formation of AgNPs cannot be excluded. Generally Ag ion reduction is facilitated by the hydroxide ion addition (Chou et al. 2005), but it has previously also been shown that Ag ions can be reduced and thus form AgNPs when peat fulvic acids (Sal'nikov et al. 2009) or humic acids (Akaighe et al. 2011) are present in the solution. With increasing amounts of humic acids in the Ag ion solution, the AgNPs formed were more polydisperse and less stable (Akaighe et al. 2011), and similarly with adding more Ag ions to fulvic acid solution, AgNPs increased both in size and polydispersity (Sal'nikov et al. 2009).

\section{Implications for consumer exposure}

The amounts of total silver released from the food containers seem negligible, as they are in $\mu \mathrm{g} / \mathrm{L}$ (or $\mathrm{ng} / \mathrm{cm}^{2}$ ) range. The highest observed $\mathrm{Ag}$ release in $3 \%$ acetic acid was for The Original Always Fresh Containers $^{\mathrm{TM}}(8.2 \pm 0.5 \mu \mathrm{g} \mathrm{Ag} / \mathrm{L})$, which amongst the containers tested in this study would result in the highest consumer exposure to Ag. Assuming a realistic household scenario of storing slightly acidic food 
item such as tomato soup or salad with vinegar, for example, in this container, one would end up ingesting $2 \mu \mathrm{g}$ of silver along with $250 \mathrm{~mL}$ portion. This amount is considered negligible according to the authorities, e.g. European Food Safety Authority (EFSA) has set the limits for total permitted migration of Ag from food contact materials to $0.05 \mathrm{mg} \mathrm{Ag} / \mathrm{kg}$ food (EFSA 2006), and also World Health Organization (WHO) has estimated a human no observable adverse effect level (NOAEL) of $\mathrm{Ag}$ to be $0.39 \mathrm{mg} / \mathrm{day}$ (World Health Organization 2004). However, these threshold values do not take the unique properties of nanomaterials into consideration and it is quite unclear what long-term effects the AgNP exposure could cause (Wijnhoven et al. 2009; Hansen and Baun 2012; SCENIHR 2014). There are currently no nano-specific regulations for silver when used in food packaging products in, for instance, the EU. In Europe, the exploitation of the antibacterial properties of AgNPs in food packaging and consumer would fall under what is known as a "treated article" under the EU's Biocidal Product Regulation, which again means that nanospecific testing and risk assessment is required. It is however unclear how to carry out a risk assessment for the nanoform of a given materials and that there is practically no guidance on how to deal with uses of biocides in consumer articles. The use of nanosilver as biocidal active ingredient under the EU biocidal products regulation's review program is currently being assessed by the Swedish Chemicals Agency (KEMI), which is known as the "the competent authority". KEMI is on public record for stating that their work is progressing slowly and it is not possible for them to say whether there is sufficient data to carry out a risk assessment on the nanoforms of silver as the data have been submitted by industry follow the usual data requirements for bulk substances (Chemical Watch 2011).

The research aimed at understanding toxicological effects of AgNPs is still full of uncertainties and knowledge gaps (Wijnhoven et al. 2009), which makes it difficult to do a comprehensive human risk assessment. Toxicity testing has shown that AgNPs are capable of penetrating through the blood-brain barrier, accumulating in the brain and subsequently cause neuron damage (Tang et al. 2008). Oral exposure to high-levels of AgNPs can also lead to blue-gray hyperpigmentation of the skin, called agyria, which 
suggests that when AgNPs reach the gastrointestinal tract, they can be distributed to other organs, including the skin (Chang et al. 2006). AgNP dislocation and accumulation to different organs, such as liver, lungs, brain, testes and kidneys has been found also after 28 days of oral exposure in rats (Kim et al. 2008). After 90 days of exposure, subchronic oral toxicity testing has shown that the target organ for AgNPs is most likely liver (Kim et al. 2010). However, it has to be noted that toxic effects are most commonly noted in $\mathrm{mg} / \mathrm{kg}$ body weight levels, which means that the oral exposure has to be quite high to observe any toxic effects. For this reason, the risk of experiencing adverse health effects as a consequence of using AgNPcontaining food containers seems negligible, but cannot be completely excluded.

The future research needs include developing tools and models for quantitative nano-specific exposure assessment, which could further assist human risk assessment to AgNPs. To get the right data, it is necessary to extensively characterize the nanoparticles that humans might be exposed to, as the toxicity can be both dose and size dependent (Park et al. 2011; Liu et al. 2010). It is especially important to improve the analytical techniques to be able to detect and quantitatively measure AgNPs in smaller sizes $(<20 \mathrm{~nm})$.

\section{Conclusions}

In conclusion, our experimental results have shown that silver has the potential of migrating into food, especially when in contact with more acidic substances. From the three food simulants used in this study, the highest total Ag migration was observed for $3 \%$ acetic acid, and migration into water and $10 \%$ ethanol was below detection limit. Nanoparticle release was observed for all four food container brands, and the general trend was that both particle size and dissolved Ag level was increased for 3\% acetic acid in comparison to other food simulants (except for Fresher Longer ${ }^{\mathrm{TM}}$ bags). TEM-EDS analysis showed that the released particles were primarily spherical, and could be found either in their dispersed form, as agglomerates, or still embedded in or attached to pieces of polymer matrix. For all four food container brands, the total Ag migration amounts did not exceed the permitted levels indicated by EFSA (2006), but 
these levels do not take the unique properties of nanomaterials into consideration. However, there are still no nano-specific regulatory limits for particle migration from the food contact materials, so the risk of consumer exposure remains unclear.

\section{Competing interests}

The authors declare that there are no competing interests. 


\section{References}

Akaighe N, MacCuspie RI, Navarro DA, Aga DS, Banerjee S, Sohn M, Sharma VK (2011) Humic acid-induced silver nanoparticle formation under environmentally relevant conditions. Environ Sci Technol 45:38953901

Artiaga G, Ramos K, Ramos L, Cámara C, Gómez-Gómez M (2014) Migration and characterisation of nanosilver from food containers by AF4-ICP-MS. Food Chem 166:76-85

Bott J, Störmer A, Franz R (2011) A Comprehensive Study into the Migration Potential of Nano Silver Particles from Food Contact Polyolefins. In: Benvenuto MA, et al. (ed) Chemistry of food, food supplements, and food contact materials: from production to plate. American Chemical Society, pp 51-70.

CFS (2014) Press release: Nonprofits Sue EPA for Failure to Regulate Novel Pesticide Products Created With Nanotechnology. Available online: http://www.centerforfoodsafety.org/press-releases/3664/nonprofitssue-epa-for-failure-to-regulate-novel-pesticide-products-created-with-nanotechnology. Accessed June 2015

Chang ALS, Khosravi V, Egbert B (2006) A case of argyria after colloidal silver ingestion. J Cutan Pathol 33:809-81

Chemical Watch (2011) Nanosilver producers refute German institute's warning. Global Business Briefing, Chemical Watch

Chou K, Lu Y, Lee H (2005) Effect of alkaline ion on the mechanism and kinetics of chemical reduction of silver. Mater Chem Phys 94:429-433. 
Cushen M, Kerry J, Morris M, Cruz-Romero M, Cummins E (2014) Silver migration from nanosilver and a commercially available zeolite filler polyethylene composites to food simulants. Food Additives \& Contaminants: Part A 31.6:1132-1140

DuPont (2013) DuPont ${ }^{\mathrm{TM}}$ Ti-Pure $^{\circledR}$ titanium dioxide. Available online:

http://www2.dupont.com/Titanium_Technologies/en_US/tech_info/literature/Plastics/DTT_H883839_Plastics_Grade.pdf . Accessed June 2015.

Echegoyen Y, Nerín C (2013) Nanoparticle release from nano-silver antimicrobial food containers. Food and Chemical Toxicology 62:16-22

EFSA (2006) Opinion of the Scientific Panel on food additives, flavourings, processing aids and materials in contact with food (AFC) on a request related to a 12th list of substances for food contact materials. The EFSA Journal 395 to 401:1-21.

European Commission (2011) Commission Regulation (EU) No. 10/2011 of 14 January 2011 on plastic materials and articles intended to come into contact with food. Off J Eur Comm 50:1-89

Hansen SF, Baun A (2012) When enough is enough. Nature nanotechnology 7:409-411

Hauri JF, Niece BK (2011) Leaching of Silver from Silver-Impregnated Food Storage Containers. J Chem Educ 88:1407-1409

Huang Y, Chen S, Bing X, Gao C, Wang T, Yuan B (2011) Nanosilver migrated into food-simulating solutions from commercially available food fresh containers. Packaging technology \& science 24:291-297

Kim YS, Kim JS, Cho HS, Rha DS, Kim JM, Park JD, Choi BS, Lim R, Chang HK, Chung YH (2008) Twenty-eightday oral toxicity, genotoxicity, and gender-related tissue distribution of silver nanoparticles in SpragueDawley rats. Inhal Toxicol 20:575-583 
Kim YS, Song MY, Park JD, Song KS, Ryu HR, Chung YH, Chang HK, Lee JH, Oh KH, Kelman BJ (2010) Subchronic oral toxicity of silver nanoparticles. Particle and fibre toxicology 7:20

Lin Q, Li B, Song H, Wu H (2011) Determination of silver in nano-plastic food packaging by microwave digestion coupled with inductively coupled plasma atomic emission spectrometry or inductively coupled plasma mass spectrometry. Food additives \& contaminants: Part A 28:1123-1128

Lin Q, Li H, Zhong H, Zhao Q, Xiao D, Wang Z (2014) Migration of Ti from nano-TiO2-polyethylene composite packaging into food simulants. Food Additives \& Contaminants: Part A. 31.7:1284-1290

Liu J, Hurt RH (2010) Ion Release Kinetics and Particle Persistence in Aqueous Nano-Silver Colloids. Environ Sci Technol 44:2169-2175

Liu W, Wu Y, Wang C, Li HC, Wang T, Liao CY, Cui L, Zhou QF, Yan B, Jiang GB (2010) Impact of silver nanoparticles on human cells: effect of particle size. Nanotoxicology 4:319-330

Pace HE, Rogers NJ, Jarolimek C, Coleman VA, Higgins CP, Ranville JF (2011) Determining transport efficiency for the purpose of counting and sizing nanoparticles via single particle inductively coupled plasma mass spectrometry. Anal Chem 83:9361-9369

Park MV, Neigh AM, Vermeulen JP, de la Fonteyne, Liset JJ, Verharen HW, Briedé JJ, van Loveren H, de Jong WH (2011) The effect of particle size on the cytotoxicity, inflammation, developmental toxicity and genotoxicity of silver nanoparticles. Biomaterials 32:9810-9817

Sal'nikov D, Pogorelova A, Makarov S, Vashurina IY (2009) Silver ion reduction with peat fulvic acids. Russian Journal of Applied Chemistry 82:545-548 
SCENIHR (2013) Opinion on Nanosilver: safety, health and environmental effects and role in antimicrobial resistance. Scientific Committee on Emerging and Newly Identified Health Risks, European Union doi:10.2772/76851

Smirnova VV, Krasnoiarova OV, Pridvorova SM, Zherdev AV, Gmoshinskii IV, Kazydub GV, Popov KI, Khotimchenko SA (2012) Characterization of silver nanoparticles migration from package materials destined for contact with foods. Voprosy pitaniia 81:34-39. (Article in Russian)

Song H, Li B, Lin Q, Wu H, Chen Y (2011) Migration of silver from nanosilver-polyethylene composite packaging into food simulants. Food Additives \& Contaminants: Part A 28:1758-1762

Tang J, Xiong L, Wang S, Wang J, Liu L, Li J, Wan Z, Xi T (2008) Influence of silver nanoparticles on neurons and blood-brain barrier via subcutaneous injection in rats. Appl Surf Sci 255:502-504

The Nanodatabase (2015) http://Nanodb.dk. Accessed November 2015

The Project on Emerging Nanotechnologies (PEN) (2013). http://www.nanotechproject.org. Accessed June 2015.

Tiede K, Boxall AB, Tear SP, Lewis J, David H, Hassellöv M (2008) Detection and characterization of engineered nanoparticles in food and the environment. Food Addit Contam 25:795-821

US EPA (2014) News Release: EPA Takes Action to Protect Public from an Illegal Nano Silver Pesticide in Food Containers; Cites NJ Company for Selling Food Containers with an Unregistered Pesticide Warns Large Retailers Not to Sell these Products. Available online:

http://Yosemite.Epa.Gov/Opa/Admpress.Nsf/0/6469952cdbc19a4585257cac0053e637?OpenDocument. Accessed June 2015 
von Goetz N, Fabricius L, Glaus R, Weitbrecht V, Gunther D, Hungerbuhler K (2013) Migration of silver from commercial plastic food containers and implications for consumer exposure assessment. Food additives \& contaminants: Part A 30:612-20

Wijnhoven SW, Peijnenburg WJ, Herberts CA, Hagens WI, Oomen AG, Heugens EH, Roszek B, Bisschops J, Gosens I, Van De Meent D (2009) Nano-silver-a review of available data and knowledge gaps in human and environmental risk assessment. Nanotoxicology 3:109-138

World Health Organization (2004) Guidelines for Drinking-Water Quality: Recommendations. Vol. 1: World Health Organization 


\section{Figures}
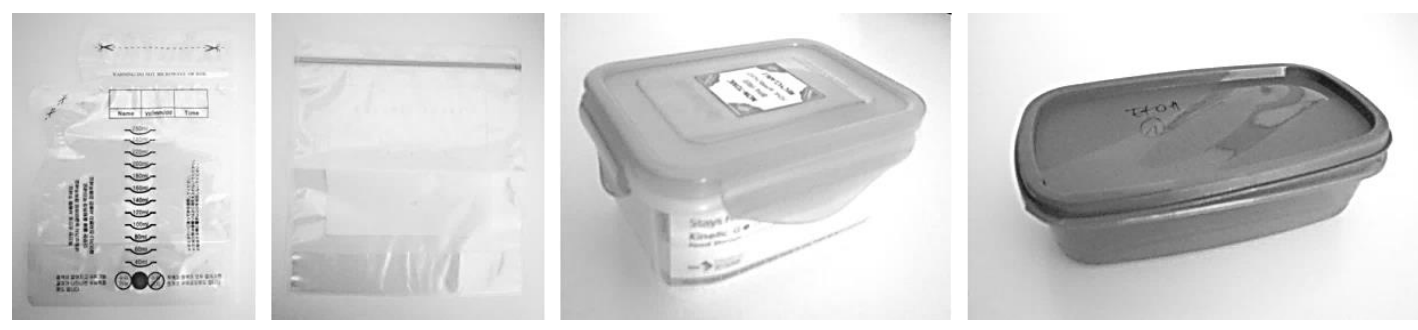

Figure 1: Plastic food containers used in this study. Starting from left side: Special Nanosilver Mother's milk pack; Fresher Longer ${ }^{\mathrm{TM}}$ Miracle Food Storage ${ }^{\mathrm{TM}}$ bags; Kinetic Go Green ${ }^{\mathrm{TM}}$ Premium Food Storage Containers; The Original Always Fresh Containers ${ }^{\mathrm{T}}$.
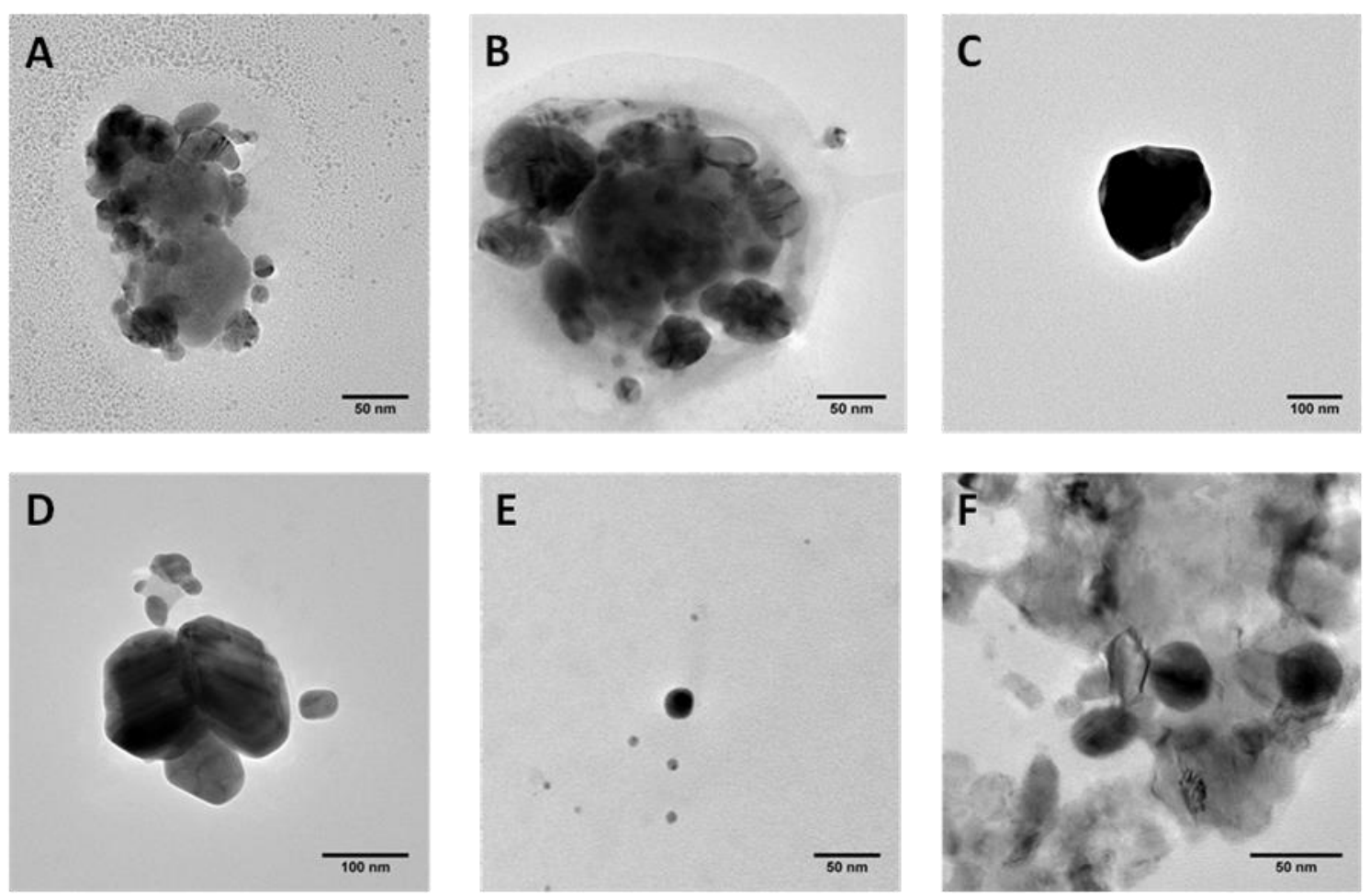

Figure 2: TEM results for migration solution samples after 10 days in 3\% acetic acid. A: Fresher Longer ${ }^{\text {TM }}$ Miracle Food Storage ${ }^{\mathrm{TM}}$ bags, B: Special Nanosilver Mother's milk pack, C and D: The Original Always Fresh Containers $^{\mathrm{TM}}, \mathrm{E}$ and F: Kinetic Go Green ${ }^{\mathrm{TM}}$ Premium Food Storage Containers. All the presented images were analyzed by EDS and confirmed the presence of silver. 


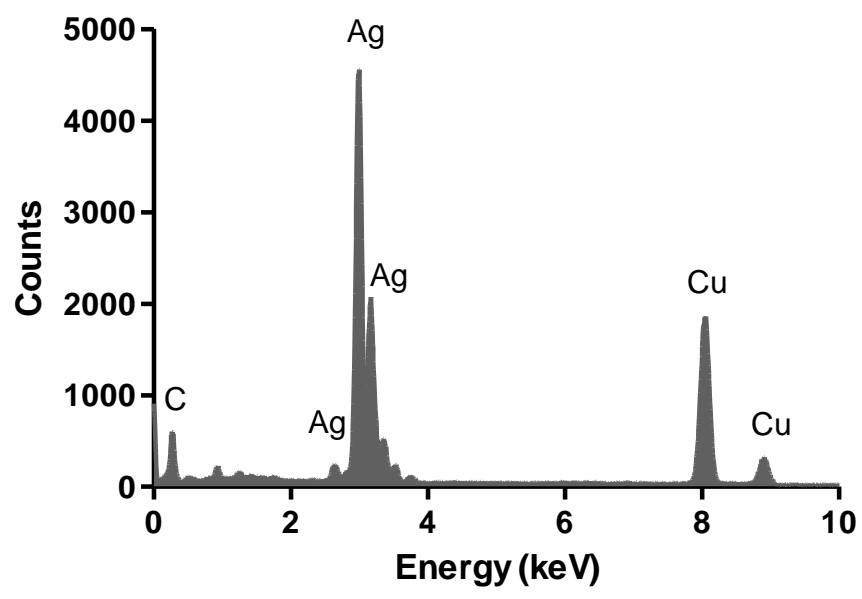

Figure 3: EDS spectrum for The Original Always Fresh Containers ${ }^{\mathrm{TM}}$ migration sample after 10 days in $3 \%$ acetic acid (Particle shown in Figure 2 D).
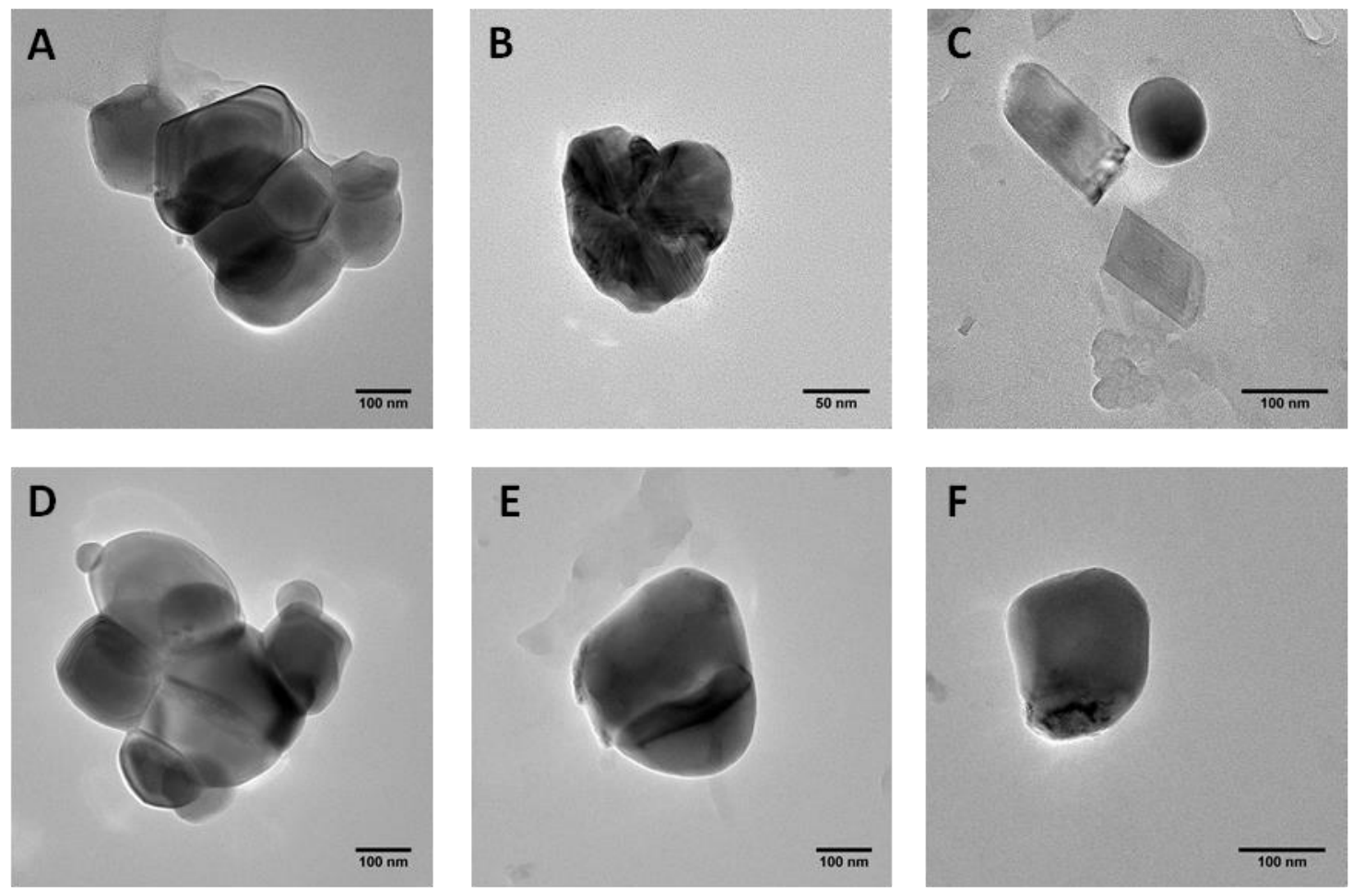

Figure 4: TEM results for migration solution samples after 10 days in 3\% acetic acid. A and B: Fresher Longer $^{\mathrm{TM}}$ Miracle Food Storage ${ }^{\mathrm{TM}}$ bags, C-F: Kinetic Go Green ${ }^{\mathrm{TM}}$ Premium Food Storage Containers. All the presented images were analyzed by EDS and confirmed the presence of titanium. 


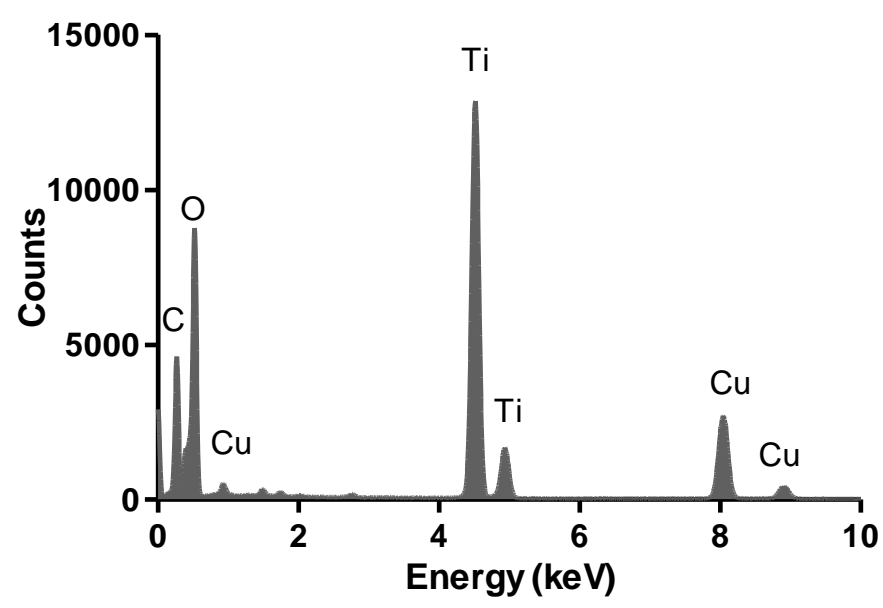

Figure 5: EDS spectrum for The Original Always Fresh Containers ${ }^{\mathrm{TM}}$ migration sample after 10 days in $3 \%$ acetic acid (Particle shown in Figure 4 D).

MilliQ
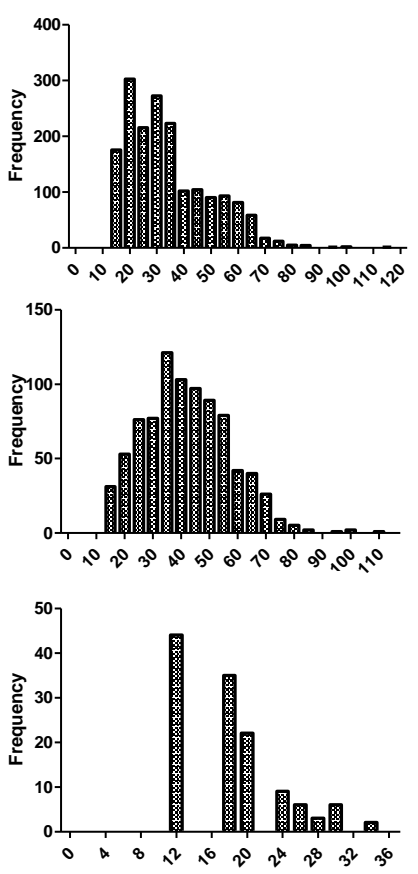

Kinetic Go Green ${ }^{\text {TM }}$ Premium

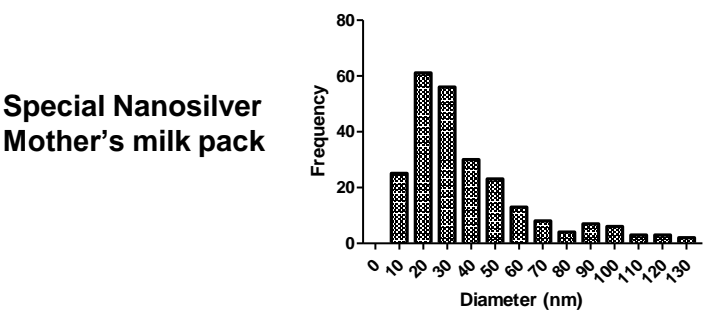

$10 \%$ Ethanol
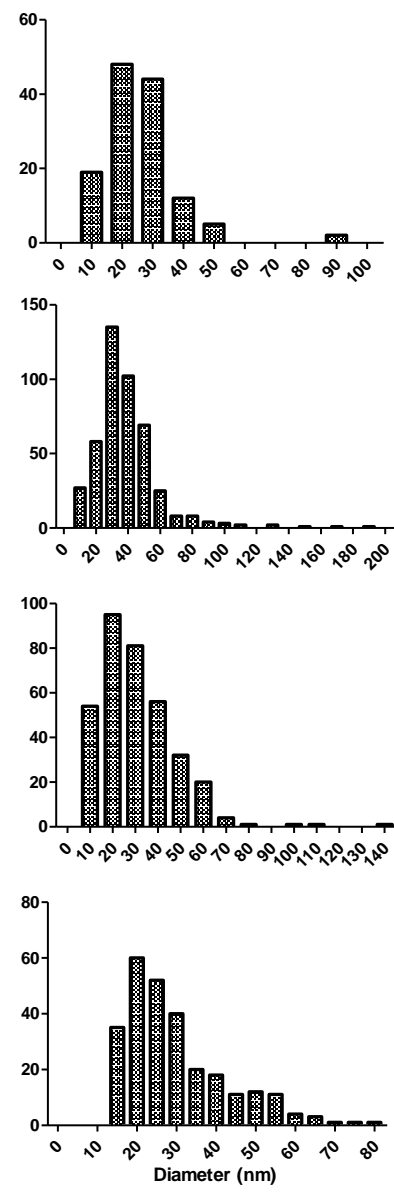
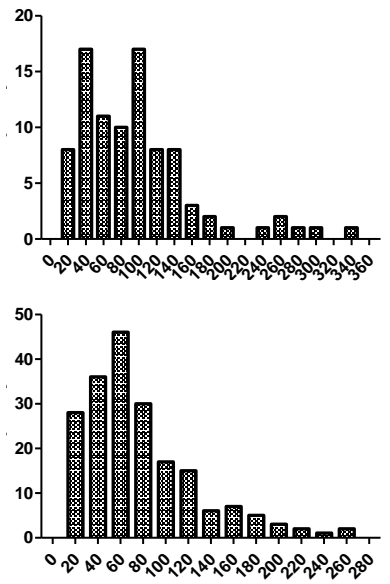

$3 \%$ Acetic acid
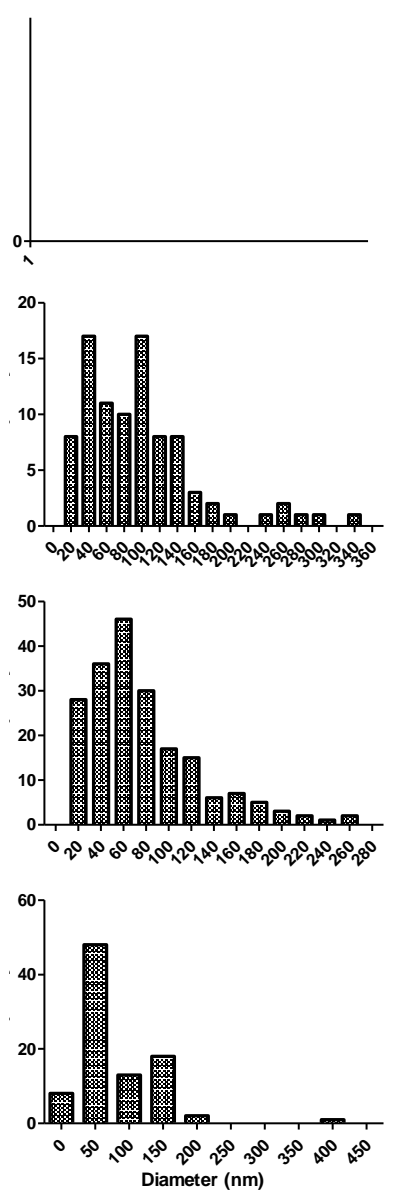

Figure 6: Particle size distributions for food containers incubated with food simulants after 10 days, measured by spICP-MS. 


\section{Tables}

Table 1: Total silver content in the food container samples and reference samples $(n=3)$.

\begin{tabular}{|c|c|c|}
\hline \multirow[b]{2}{*}{ Product } & \multicolumn{2}{|c|}{ Total Ag content } \\
\hline & $\mu \mathrm{g} / \mathrm{g}$ & $\mu \mathrm{g} / \mathrm{cm}^{2}$ \\
\hline PE granulates (control) & $<1.0$ & - \\
\hline Fresher Longer ${ }^{\mathrm{TM}}$ Miracle Food Storage ${ }^{\mathrm{TM}}$ bags & $22.5 \pm 0.4$ & $0.2 \pm 0.0$ \\
\hline The Original Always Fresh Containers ${ }^{\mathrm{TM}}$ & $11.9 \pm 3.3$ & $1.4 \pm 0.4$ \\
\hline Kinetic Go Green ${ }^{\mathrm{TM}}$ Premium & $<1.0$ & $<0.2$ \\
\hline Special Nanosilver Mother's milk pack & $31.2 \pm 4.8$ & $0.2 \pm 0.0$ \\
\hline
\end{tabular}

Table 2: Total silver content in the food simulants after 10 days of incubation.

\begin{tabular}{|c|c|c|c|}
\hline \multirow[b]{2}{*}{ Product } & \multirow[b]{2}{*}{ Release medium } & \multicolumn{2}{|c|}{ Total Ag release } \\
\hline & & $\mu g / L$ & $\mathrm{ng} / \mathrm{cm}^{2}$ \\
\hline \multirow[t]{3}{*}{ PE granulates (control) } & MilliQ & $<0.9$ & - \\
\hline & $10 \%$ Ethanol & $<0.9$ & - \\
\hline & $3 \%$ Acetic acid & $<0.9$ & - \\
\hline Fresher Longer ${ }^{\mathrm{TM}}$ Miracle & MilliQ & $<0.9$ & $<0.4$ \\
\hline \multirow[t]{2}{*}{ Food Storage ${ }^{\mathrm{TM}}$ bags } & $10 \%$ Ethanol & $<0.9$ & $<0.4$ \\
\hline & $3 \%$ Acetic acid & $4.1 \pm 0.5$ & $2.0 \pm 0.2$ \\
\hline The Original Always & MilliQ & $<0.9$ & $<0.4$ \\
\hline \multirow[t]{2}{*}{ Fresh Containers $^{\mathrm{TM}}$} & $10 \%$ Ethanol & $<0.9$ & $<0.3$ \\
\hline & 3\% Acetic acid & $8.2 \pm 0.5$ & $2.7 \pm 0.2$ \\
\hline Kinetic Go Green ${ }^{\mathrm{TM}}$ & MilliQ & $<0.9$ & $<0.5$ \\
\hline \multirow[t]{2}{*}{ Premium } & $10 \%$ Ethanol & $<0.9$ & $<0.5$ \\
\hline & $3 \%$ Acetic acid & $5.5 \pm 1.7$ & $2.8 \pm 0.9$ \\
\hline Special Nanosilver & MilliQ & $<0.9$ & $<0.6$ \\
\hline \multirow[t]{2}{*}{ Mother's milk pack } & $10 \%$ Ethanol & $<0.9$ & $<0.6$ \\
\hline & $3 \%$ Acetic acid & $4.9 \pm 1.0$ & $3.1 \pm 0.7$ \\
\hline
\end{tabular}


Table 3: Dissolved and particulate Ag leached into food simulants, measured by spICP-MS.

\begin{tabular}{|c|c|c|c|c|c|}
\hline Product & Release medium & $\begin{array}{l}\text { Dissolved Ag } \\
(\mu \mathrm{g} / \mathrm{L})\end{array}$ & $\begin{array}{l}\text { Particulate } \mathrm{Ag} \\
\left(10^{6} \text { particles } / \mathrm{L}\right)\end{array}$ & $\begin{array}{l}\text { Particulate Ag } \\
\text { (ng/L) }\end{array}$ & $\begin{array}{l}\text { Median size } \\
\text { (nm) }\end{array}$ \\
\hline Fresher Longer ${ }^{\mathrm{TM}}$ & MilliQ & - & 37.6 & 13.9 & 30.3 \\
\hline Miracle Food & $10 \%$ Ethanol & - & 2.8 & 0.5 & 23.9 \\
\hline Storage $^{T M}$ bags & 3\% Acetic acid & 6.79 & - & - & - \\
\hline The Original Always & MilliQ & 0.57 & 18.3 & 10.5 & 41.1 \\
\hline \multirow[t]{2}{*}{ Fresh Containers $^{\mathrm{TM}}$} & $10 \%$ Ethanol & 0.66 & 9.5 & 7.1 & 35.5 \\
\hline & 3\% Acetic acid & 10.71 & 2.0 & 27.5 & 89.6 \\
\hline Kinetic Go Green ${ }^{\mathrm{TM}}$ & MilliQ & - & 2.7 & 0.1 & 17.4 \\
\hline \multirow[t]{2}{*}{ Premium } & $10 \%$ Ethanol & 0.13 & 7.4 & 2.5 & 26.9 \\
\hline & $3 \%$ Acetic acid & 3.18 & 4.2 & 27.8 & 67.2 \\
\hline Special Nanosilver & MilliQ & 0.03 & 5.5 & 4.5 & 29.8 \\
\hline \multirow[t]{2}{*}{ Mother's milk pack } & $10 \%$ Ethanol & - & 5.8 & 1.4 & 25.5 \\
\hline & 3\% Acetic acid & 7.51 & 1.9 & 18.3 & 63.8 \\
\hline
\end{tabular}

